\title{
Investigation of Stability of a Slope Subjected to Water Table and Seismic Load
}

\author{
Md. Akhtar Hossain, PhD \\ Associate Professor, \\ Department of Civil \\ Engineering \\ Rajshahi University of \\ Engineering \& Technology, \\ Rajshahi
}

\author{
Md. Abdul Mukit \\ Department of Civil \\ Engineering \\ Rajshahi University of \\ Engineering \& Technology, \\ Rajshahi
}

\author{
Md. Golam Kibria \\ Department of Civil \\ Engineering \\ Rajshahi University of \\ Engineering \& Technology, \\ Rajshahi
}

\begin{abstract}
The stability of the slopes is the major concern in the field of Geotechnical Engineering. Usually three methods of analysis have been proposed for the evaluation of slopes response under seismic loads. These three methods are Pseudo-static method, Newmark's displacement method and Dynamic finite element analysis method. In Pseudo-static method the earthquake's inertial forces are simulated by the inclusion of static horizontal seismic acceleration co-efficient $\left(\mathrm{k}_{\mathrm{h}}\right)$ and vertical seismic acceleration co-efficient $\left(\mathrm{k}_{\mathrm{v}}\right)$ in limit equilibrium analysis. It is one of the most dangerous conditions of natural slope when it experiences a seismic vibration the countervailing water pressure has disappeared, it causes a danger to the slope. In this work, by applying the Morgenstern-Price presented by the computer program SLOPE/W was applied to define the potential slip surface and calculate the factor of safety of the defined slope for the maximum horizontal seismic acceleration co-efficient $\left(k_{h}\right)$. Calculation of relative lateral displacement of the slope surface and deformed shape of the defined slope due to the effects of horizontal seismic acceleration were done with the help of QUAKE/W software analysis. It was founded that the stability of the defined slope rapidly decreased.
\end{abstract}

\section{Keywords}

Pseudo-Static Method, Morgenstern-Price Method (LEM), Dynamic Finite Element Method (FEM), Horizontal seismic acceleration co-efficient $\left(\mathrm{k}_{\mathrm{h}}\right)$, Factor of safety, Relative lateral displacement.

\section{INTRODUCTION}

Slope failure, a natural disaster that occurs around the world, can be induced by earthquake loadings and can lead to severe damage/destruction in properties and loss of lives. For example, Chichi-Taiwan 1999's earthquake ( $\mathrm{Ms}=7.6$ ) destroyed 8500 buildings, heavily damaged about 6200 others, generated thousands of landslides and left 100,000 people homeless.

Lebanon and the Mediterranean area are located in an active seismic zone that increases the failure risk of naturally sloped soils. This has led to a continuously increasing interest in the analysis of slope sta bility under seismic loading.

The overstress of a slope or the reduction in the shear strength of its soil may cause a slope to displace. Engineers analyze slope to calculate quantitative indicators of performance such as factor of safety, lateral deformation, probability of failure and reliability index. Slope stability analysis includes static and dynamic stability of earth slopes, natural slopes, cut slopes, embankments, landslides, etc. These slopes can be formed out of soil or rock [1].

Stability of a slope can be affected by seismicity in two ways: earthquake and blasting. These seismic motions are capable of inducing large destabilizing inertial forces.

It is one of the earliest procedures for seismic slope stability analysis is the load-based procedure, in which the earthquake loading is represented by a horizontal static force, equal to the soil weight multiplied by a coefficient, which can be estimated by empirical guidelines or codes [2]. The pseudostatic force is then integrated in a conventional limit equilibrium slope stability analysis and the factor of safety is computed. The computed factor of safety provides an indication of the possible magnitude of seismically induced displacement [3].

A general method of slices was developed on the basis of limit equilibrium. It requires satisfying equilibrium of forces and moments acting on individual blocks. The blocks are created by dividing the soil above the slip surface by dividing planes [4]. Forces acting on individual blocks are displayed in the following figure:

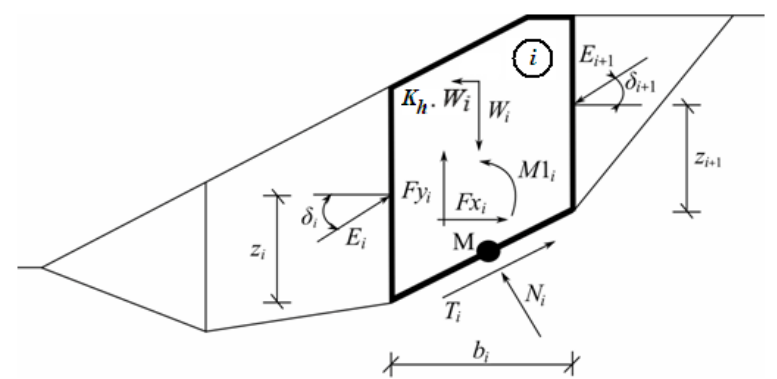

Static scheme - Morgenstern-Price method

Each block is assumed to contribute due to the same forces as in Spencer method. The following assumptions are introduced in the Morgenstern-Price method to calculate the limit equilibrium of forces and moment on individual blocks:

- dividing planes between blocks are always vertical

- the line of action of weight of block $\mathrm{W}_{\mathrm{i}}$ passes through the center of the $i^{\text {th }}$ segment of slip surface represented by point $M$

- the normal force $\mathrm{N}_{\mathrm{i}}$ is acting in the center of the $\mathrm{i}^{\text {th }}$ segment of slip surface, at point $\mathrm{M}$

- inclination of forces $E_{i}$ acting between blocks is different on each block $\left(\delta_{\mathrm{i}}\right)$ at slip surface end points is $\delta=0$ 
Finally, after simplifications some equations he gave a formula to calculate FS. That is

$$
F S=\tan \varphi_{i} \cdot \tan \left(\delta_{i+1}-\alpha_{i}\right) .
$$

An alternative approach is to assess the exact amount of movement that the slope would underground a specific seismic load. There were many researchers who were worked in displacement-based seismic slope analysis and gave some conclusions.

One of the approach for displacement of a mass of soil above a slip surface is represented as a rigid block sliding on a plane surface. When the ground motion exceeds the critical acceleration, the block begins to slip along the plane. Movements continue until the velocity of the block relative to the underlying mass becomes zero. The block will slide again if the ground motion exceeds the critical acceleration [5].

A two-block sliding model was developed for the calculation of displacements in the post-seismic stage, immediately after the earthquake. It simulates the motion of a slide that can be approximated by two plane shear surfaces with minimal internal disruption. In this stage movements will begin with a static factor of safety less than unity, and a section of the slope will move under gravity to a new position of equilibrium. It is assumed that the slope a finite length and that the mass slips on a surface produced by the earthquake during the first stage. It is also assumed that the slip surface consists of two slip planes[6]. There were certain limitations in the above model.

Therefore, a more general multi-block dynamic model was developed for the calculation of sliding displacements using an approach similar to, but more general. The model relies on the assumption that the pseudo-static limiting equilibrium conditions could provide the failure mechanism on which to construct and configure the dynamic system. A failure mechanism is needed for the application of the multi-block dynamic model and if the slope starts to move, the failure mechanism has to be cinematically acceptable [7].

\section{METHODOLOGY}

A simple example with an idealized slope model is analyzed by the most common Limit Equilibrium (LM) Methods. In this chapter a layered soil slopes for both conditions with and without water tables under the seismic loads condition using Morgenstern-Price method by the Slope/w software are analyzed.

For the dynamic conditions of the defined slopes are analyzed with the help of Quake/w software. In case of dynamic analysis Finite Element (FE) Method (Equivalent Linear method) is used in which materials are modeled Equivalent Linear method.

\subsection{Stability analysis of a slope at static condition}

From our thesis work using SLOPE/W software on the basis of LEM (Morgenstern-Price method) the analyses have been represented by various graphs to illustrate the effects of earthquake of the proposed layered soil slope for both dry and wet conditions are given below:
Table 1. Input Parameters for Analysis

\begin{tabular}{|c|c|c|c|}
\hline Soil type & $\begin{array}{c}\text { Unit } \\
\text { weight, } \boldsymbol{\gamma} \\
\left(\mathbf{k N} / \mathbf{m}^{\mathbf{3}}\right)\end{array}$ & $\begin{array}{c}\text { Cohesion,c } \\
(\mathbf{k P a})\end{array}$ & $\begin{array}{c}\text { Friction } \\
\text { angle, } \boldsymbol{\varphi} \\
(\mathbf{d e g})\end{array}$ \\
\hline Layer 1 & 16 & 20 & 16 \\
\hline Layer 2 & 17 & 25 & 12 \\
\hline Layer 3 & 19 & 30 & 10 \\
\hline
\end{tabular}

Table 2. Additional Soil Parameters Used for Dynamic Analysis

\begin{tabular}{|c|c|c|c|}
\hline Soil type & $\begin{array}{c}\text { Damping } \\
\text { ratio }\end{array}$ & $\begin{array}{c}\text { Poisson's } \\
\text { ratio }\end{array}$ & $\mathbf{G}_{\max }(\mathbf{k P a})$ \\
\hline Layer 1 & 0.1 & 0.33 & 5000 \\
\hline Layer 2 & 0.1 & 0.33 & 5000 \\
\hline Layer 3 & 0.1 & 0.33 & 5000 \\
\hline
\end{tabular}

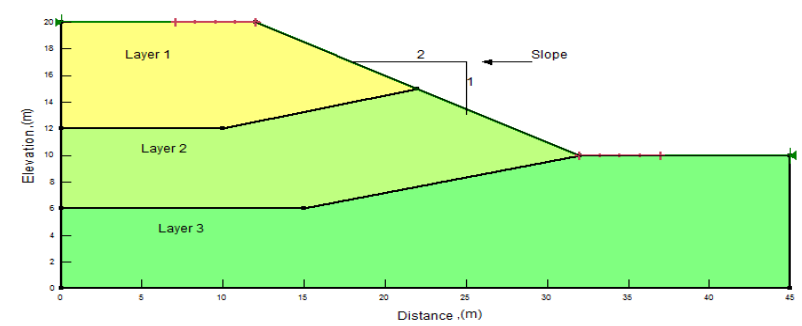

Fig 1: Slope of layered soil without water table

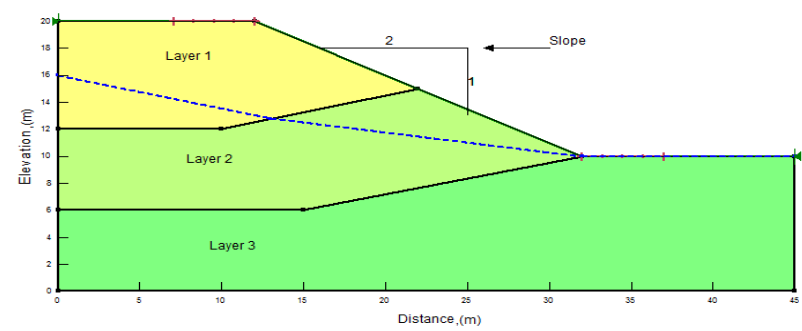

Fig 2: Slope of layered soil with water table

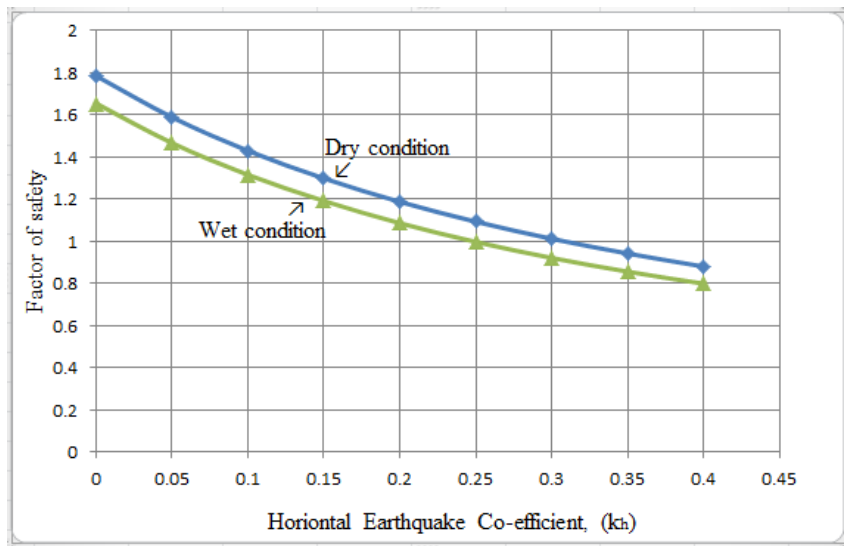

Fig3: Variation of factor of safety with respect to horizontal earthquake co-efficient $\left(k_{h}\right)$ in both dry and existing water table condition 
The above graph shows that the factor of safety is gradually decreases with the increases of horizontal earthquake coefficient $\left(\mathrm{k}_{\mathrm{h}}\right)$. It also indicates that the defined slope will be unstable when the value of horizontal earthquake co-efficient $\left(\mathrm{k}_{\mathrm{h}}\right)$ is more than 0.30 in dry condition and 0.25 for wet condition. So dry slope is more stable.

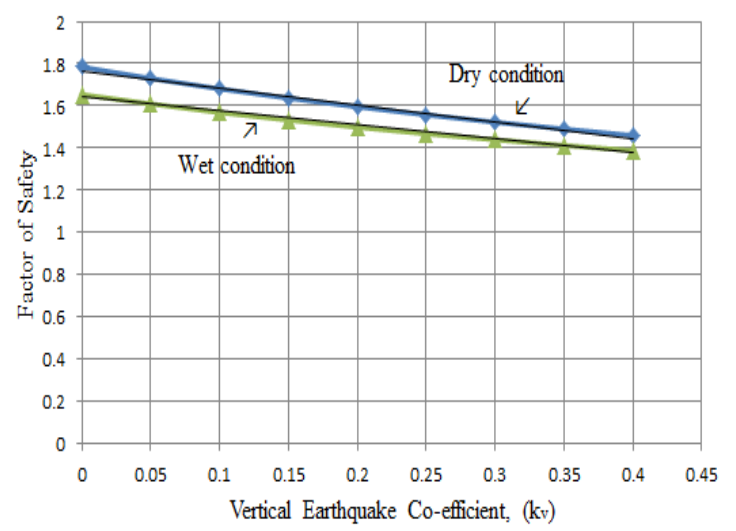

Fig 4: Variation of factor of safety with respect toVerticalearthquake co-efficient $\left(k_{v}\right)$ in both dry and existing water table condition

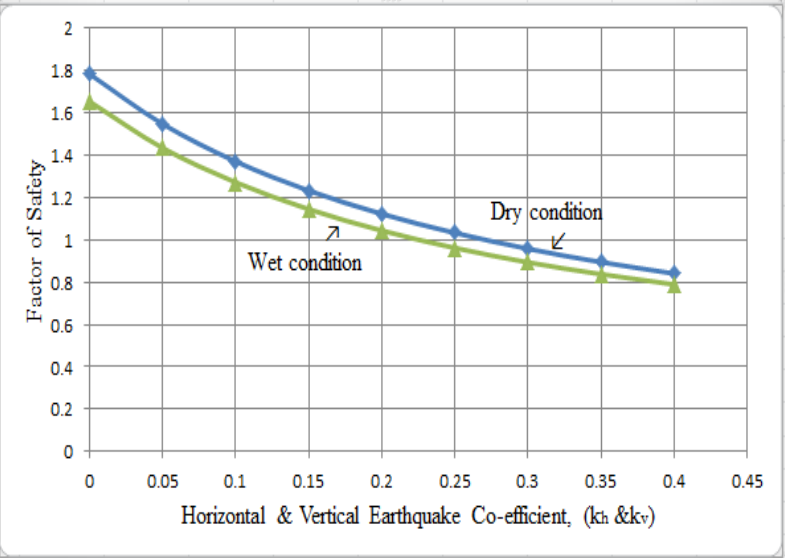

Fig 5: Variation of factor of safety with respect to Horizontal \& Vertical earthquake co-efficient $\left(k_{h} \& k_{v}\right)$ in both dry and existing water table condition

From figure 3, $4 \& 5$ it is clear that the effects of horizontal earthquake co-efficient $\left(\mathrm{k}_{\mathrm{h}}\right)$ is too more than the Vertical earthquake co-efficient $\left(\mathrm{k}_{\mathrm{v}}\right)$. But the combine effects for the same of $\left(\mathrm{k}_{\mathrm{h}}\right)$ and $\left(\mathrm{k}_{\mathrm{v}}\right)$ is slightly more than the effects of $\left(\mathrm{k}_{\mathrm{h}}\right)$. So we can say that horizontal earthquake co-efficient $\left(k_{h}\right)$ is the major culprit to decrease the stability of a slope during earthquake.

\subsection{Stability analysis of a slope at dynamic condition}

From the dynamic analysis of the defined slope some important figures are given below to understand the slope features clearly. It means that what actually happens of the defined slope due to the effect of horizontal earthquake acceleration.

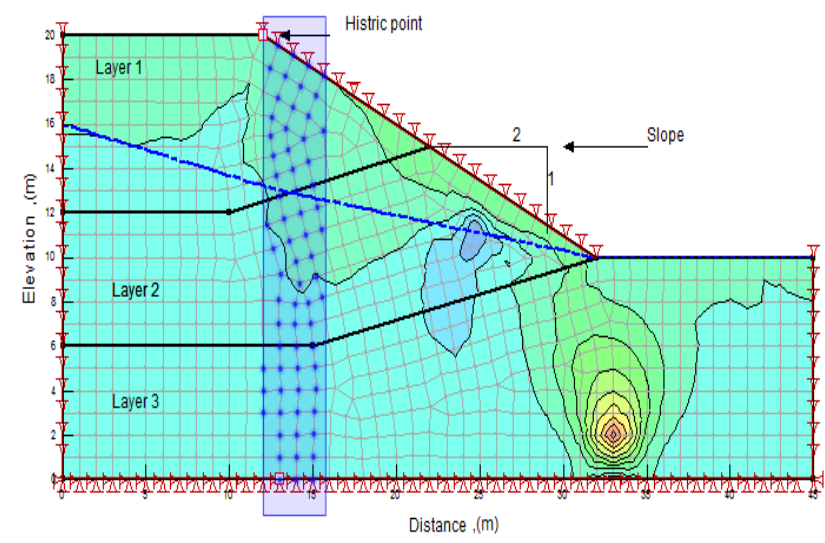

Fig 6 : Relative lateral displacement

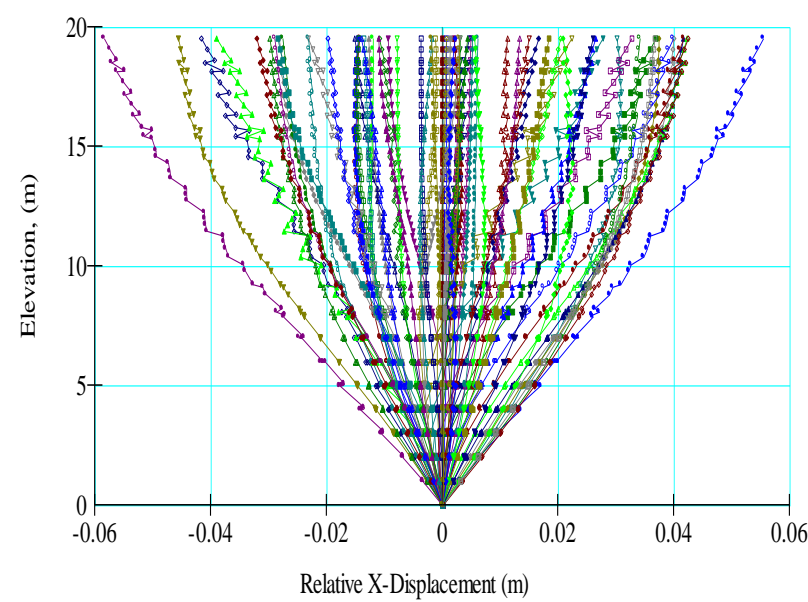

Fig 7: Relative displacement in $\mathrm{X}$ direction along $\mathrm{Y}$ axis for the shaded area which is given in Fig 6

The above graph 7 is taken from the 500 steps of 10 seconds horizontal earthquake acceleration $(\mathrm{g})$ record in 0.02 second time interval. To clearly understand the average relative horizontal displacement graph is given below along $\mathrm{Y}$ axis of the shaded area in fig. 6 .

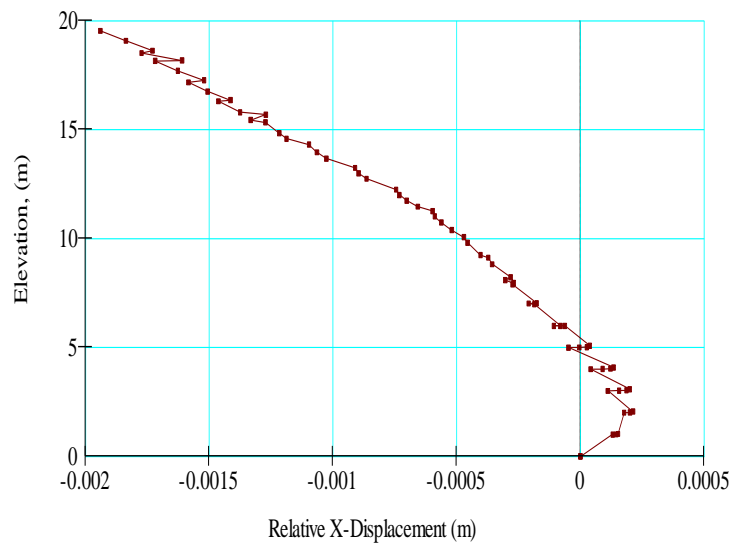

Fig. 8 : Average relative displacement in $\mathrm{X}$ direction along $\mathrm{Y}$ axis for the shaded area which is given in Fig 7

The above graph 8 shows that the maximum lateral relative displacement in $\mathrm{X}$ direction along $\mathrm{Y}$ axis for the shaded area 
which is given in Fig 6. at the top of the defined slope and almost zero at the bottom of the slope.

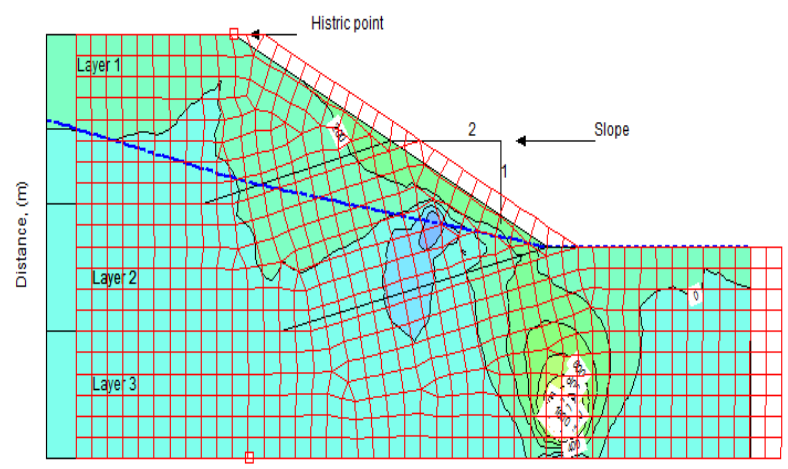

Distance, $(m)$

Fig 9 : Relative lateral movement due to the effect of horizontal earthquake acceleration (g)

\section{CONCLUSIONS}

This study presents the analysis of the stability of $20 \mathrm{~m}$ height layered soil slope using SLOPE/W and QUAKE/W. The following conclusions were drawn from the obtained results:

- For both dry and existing water table conditions factor of safety of the defined slope gradually decreases with the increase of horizontal earthquake acceleration co-efficient $\left(\mathrm{k}_{\mathrm{h}}\right)$.

- The effects of horizontal earthquake acceleration co-efficient $\left(\mathrm{k}_{\mathrm{h}}\right)$ is too more than vertical earthquake acceleration co-efficient $\left(\mathrm{k}_{\mathrm{v}}\right)$. But the combine effects of $k_{h}$ and $k_{v}$ for the same value of $k_{h}$ and $k_{v}$ is slightly more than the only effects of horizontal earthquake acceleration co-efficient $\left(\mathrm{k}_{\mathrm{h}}\right)$.

- The value of factor of safety in dry condition is more than the existing water table condition of the defined slope.
- The soil particles of the layered slope may be laterally displaced when it experienced horizontal earthquake acceleration.

- The lateral relative displacement of the layered slope for both dry and existing water table conditions are non linearly increase during horizontal earthquake acceleration and it becomes maximum at the top of the slope and zero at the bottom of the slope.

\section{REFERENCES}

[1] I., Fadi H.C., and Riad A.W. 2014. Slope Stability Analysis Under Seismic Loading. Second European conference on earthquake engineering and seismology, Istambul.

[2] Ding, T. 2006. seismic slope safety - determination of critical slip surface using acceptability criteria. A thesis submitted to the university of London in partial fulfillment for the degree of doctor of philosophy and diploma of imperial college London.

[3] Seed, H. 1979. Considerations in the earthquake-resistant design of earth and rockfill dams. Géotechnique, 29(3), pp. 215-263.

[4] Morgenstern, N.R., and Price, V.E. 1967. A numerical method for solving the equations of stability of general slip surfaces. Computer Journal, 9: 388-393.

[5] Newmark, N. M. 1965. Effects of earthquakes on dams and embankments. Geotechnique, 15(2), pp. 139-160.

[6] Ambraseys, N., and Srbulov, M. 1995. Earthquake induced displacements of slopes. Soil Dynamics and Earthquake Engineering, 14(1), pp. 59-71.

[7] Chlimintzas, G. O. 2003. Seismic displacements of slopes using multi-block. Ph.D. Dissertation, Imperial College London, Civil Engineering Department, Soil Mechanics and Engineering Seismology Section. 